\title{
The Power of Three: A Latent Class Analysis of the Three Parent- Child Relationships in Stepfamilies and Their Influence on Emerging Adult Outcomes
}

Braquel Rachel Egginton

Brigham Young University

Follow this and additional works at: https://scholarsarchive.byu.edu/etd

Part of the Social and Behavioral Sciences Commons

BYU ScholarsArchive Citation

Egginton, Braquel Rachel, "The Power of Three: A Latent Class Analysis of the Three Parent-Child Relationships in Stepfamilies and Their Influence on Emerging Adult Outcomes" (2018). Theses and Dissertations. 7452.

https://scholarsarchive.byu.edu/etd/7452

This Thesis is brought to you for free and open access by BYU ScholarsArchive. It has been accepted for inclusion in Theses and Dissertations by an authorized administrator of BYU ScholarsArchive. For more information, please contact ellen_amatangelo@byu.edu. 
The Power of Three: A Latent Class Analysis of the Three Parent-Child Relationships in Stepfamilies and Their Influence on Emerging Adult Outcomes

Braquel Rachel Egginton

A thesis submitted to the faculty of

Brigham Young University

in partial fulfillment of the requirements for the degree of

Master of Science

Erin Kramer Holmes, Chair

Alan J. Hawkins

Spencer L. James

School of Family Life

Brigham Young University

Copyright (C 2018 Braquel Rachel Egginton

All Rights Reserved 


\begin{abstract}
The Power of Three: A Latent Class Analysis of the Three Parent-Child Relationships in Stepfamilies and Their Influence on Emerging Adult Outcomes
\end{abstract}

\author{
Braquel Rachel Egginton \\ School of Family Life, BYU \\ Masters of Science
}

\begin{abstract}
Research on stepfamilies strongly supports the importance of positive parent-child relationships on child outcomes. However, most of this research has focused on one or two of these relationships failing to acknowledge the interconnected impact of all three parental figures. To fill this gap, I used latent class analysis and identified six classes of parent-child relationship constellations. The national sample in this study $(n=1,159)$ were all participants in The Stepfamily Experiences Project (STEP). Parent-child relationship quality indicators were based on participants' retrospective reports on the warmth/closeness, communication, and level of active parenting they experienced in their stepfamily household. After identifying classes I examined how class membership was affected by resident parent relationships status, EA sex, stepparent sex, years spent in a stepfamily, the age the EA entered the stepfamily and the time spent with the nonresident parent. Finally, I examined how class membership impacted depression, drug use, and hooking up. Ultimately, the analysis indicated that there is much complexity in the stepfamily experience and its potential influence on later life outcomes.
\end{abstract}

Keywords: stepfamily, parent-child relationship, emerging adult, years in stepfamily, sex, gender, parental relationship status, depression, drug use, hooking up 


\section{ACKNOWLEDGMENTS}

This has been a long, tiring and, at some points, infuriating process of writing and rewriting, but I appreciate everyone who has helped me thus far. First and foremost I wanted to thank Erin Holmes who helped me redirect my life toward the best career option I could have taken and for all her tireless work reading and rereading my many, many drafts. Thanks to Spencer James, Joe Olsen, and Adam Galavan for their statistical support. There would have been no paper without all the hours they put in. Finally thank you to Alan Hawkins and Alex Jensen for challenging me to enter a whole new level of writing. I would never have gotten this far without all of you. 


\section{Table of Contents}

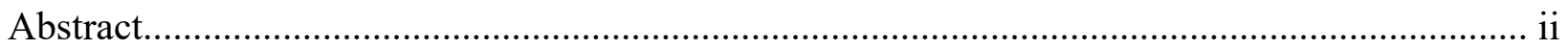

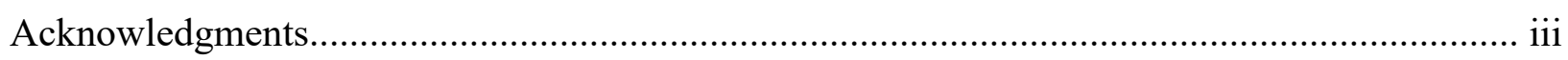

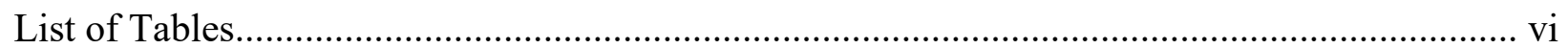

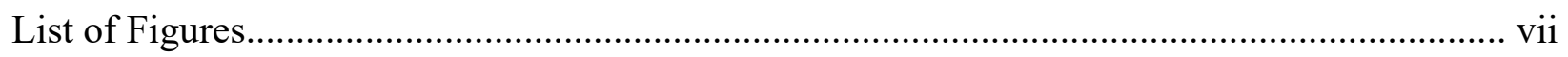

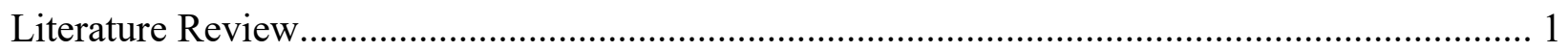

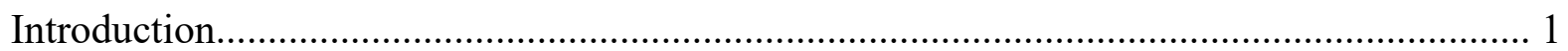

Theoretical Perspective................................................................................................ 2

Patterns of Parent-Child Relationships.................................................................... 4

Predictors of Parent-Child Relationship Quality ...................................................... 6

The Impact of Stepfamily Life on Emerging Adults.................................................... 8

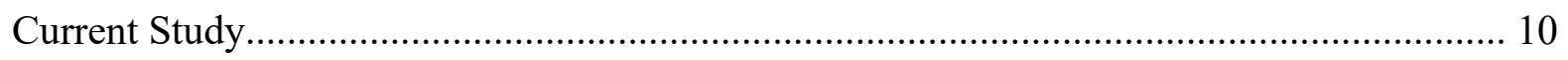

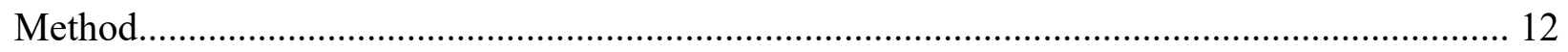

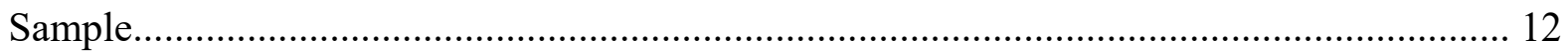

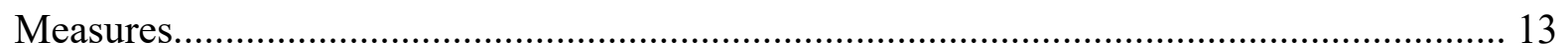

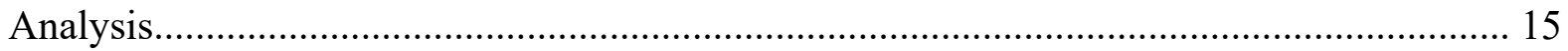

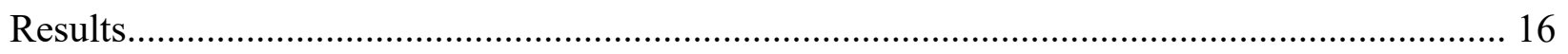

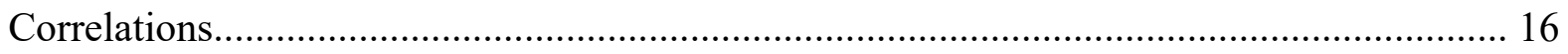

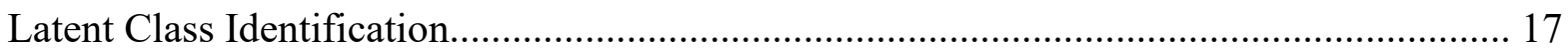

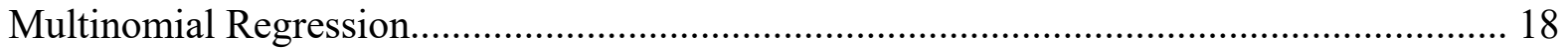

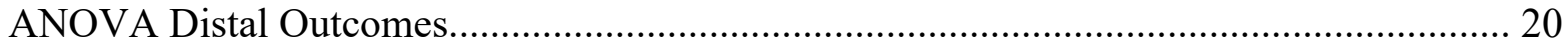

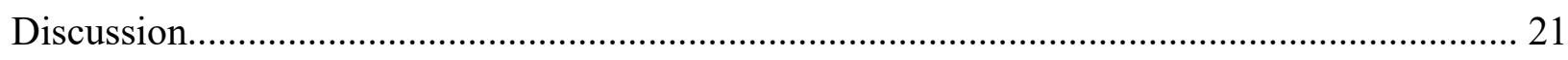

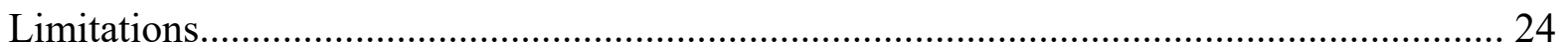




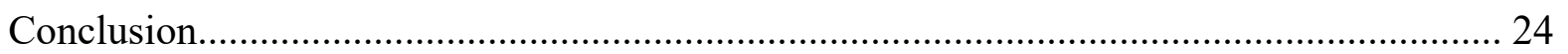

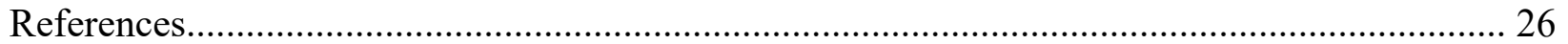




\section{List of Tables}

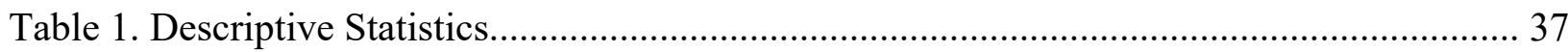

Table 2. Correlations of Class Indicators, Independent variables, and Distal Outcomes............ 38

Table 3. Model Fit Statistics for Determining Number of Classes........................................... 39

Table 4. T-tests of Difference between Classes.................................................................... 40

Table 5. Multinomial Logistic Regression of Resident Parent Relationship Status across

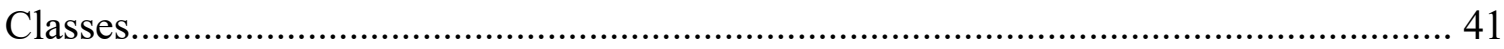

Table 6. Multinomial Logistic Regression of EA Sex across Classes..................................... 42

Table 7. Multinomial Logistic Regression of Stepparent Sex across Classes.......................... 43

Table 8. Multinomial Logistic Regression of the Years Spent in a Stepfamily across Classes... 44

Table 9. Multinomial Logistic Regression of Age at Stepfamily Formation across Classes...... 45

Table 10. Multinomial Logistic Regression of the Quantity of Time Spent with the Nonresident

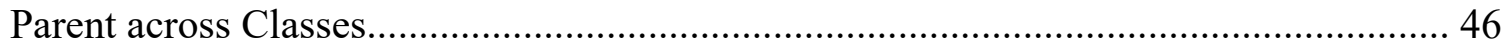

Table 11. Means and SEs of Class Differences on Distal Outcomes....................................... 47 


\section{List of Figures}

Figure 1. Analysis Model.................................................................................................. 48

Figure 2. Latent Classes of Parent-Child Relationships..................................................... 49 
The Power of Three: A Latent Class Analysis of the Three Parent-Child Relationships in Stepfamilies and Their Influence on Emerging Adult Outcomes

\section{Literature Review}

\section{Introduction}

Individuals who have experienced stepfamilies as children or adolescents have undergone at least two major life transitions: the permanent or temporary loss of a biological parent, and the entrance of a third, nonbiological parent into their family system (Hetherington, Cox, \& Cox, 1985). Each ensuing family transition increases their susceptibility to negative behavioral outcomes such as depression (Barrett \& Turner, 2006; Sheets \& Craighead, 2014), drug use (Flewelling \& Bauman, 1990; Hoffman \& Johnson, 1998), and risky sexual behavior (Owen, Rhoades, Stanley, \& Fincham, 2010). As these individuals progress from childhood and adolescence into emerging adulthood these behaviors can negatively affect their ability to develop long-term relationships and obtain professions that promote self-sufficiency (Crawford \& Novak, 2008; Sheets \& Craighead, 2014).

However, while the average individual may experience increased struggles in the stepfamily environment, many still experience positive outcomes (Ganong \& Coleman, 2017; Sweeny, 2010). How is it that some individuals who enter stepfamily life in childhood or adolescence are able to develop positive outcomes? Parental relationships have been widely known to be one of the most influential factors contributing to both positive and negative child outcomes (Bornstein, 2002). Unfortunately, much of the research on parent-child relationships in stepfamilies has focused on relationships between one parent and the child failing to fully acknowledge the impact one positive — or negative — parent-child relationship might have on the other parent-child relationships (Coleman, Ganong, \& Russell, 2013). To my knowledge there is 
only one research article that specifically examines the impact of parental warmth from all three parental figures present in stepfamilies that follow a divorce (Amato, King, \& Thorsen, 2016). In their adolescent sample, Amato et al. (2016) examined the number of warm parent-child relationship patterns that form in married, stepfather families. They found 4 classes that were significantly influenced by a range of independent variables including the sex of the adolescent, the age of the adolescent, the years spent in the stepfamily and the stepfather's education. Class membership had a significant impact on outcomes of depression, drug use and delinquency in their adolescent sample. The purpose of this study is to build on their findings by examining emerging adult families who lived in a stepfamily at some point between the ages of 0 and 18 . In addition I included both stepmother and stepfather families that were either cohabiting or married. I also expanded my class indicators to include warmth, communication and active parenting. Finally, while I also examine depression and drug use, I decided to examine hooking up behaviors rather than delinquency.

The purpose of this analysis is to (a) identify the potential parent-child relationships patterns that form in stepfamily relationships, (b) identify factors that may influence the development of these relationships and (c) examine the impact of these differing parent-child relationships patterns on emerging adult (EA) depression, drug use, and hooking up.

\section{Theoretical Perspective}

Life Course theory offers the primary theoretical framework for this analysis. This theory asserts that individuals experience transitions, or changes throughout their lives that have the potential for both positive and negative effects on later life transitions (Elder, 1998). These transitions influence individuals and their family members because their lives are linked (Elder, Johnson, \& Crosnoe, 2003) or, in the words of family systems theorists, interdependent 
(Minuchin, 1985). While it is inevitable that individuals, and subsequently their families, will eventually experience change and transition in family structure and process, both the timing and meaning given to these transitions are significant indicators of the impact they will have. When transitions occur in combination with crises, and require significant adjustment in an individual's life, they are more likely to have significant impact for both good and bad. Divorce and stepfamily life are both examples of transitions that are often associated with crises and significant life adjustment. As a result, they can have severe negative impacts on EAs who experience these transitions during their childhood or adolescence. However, the interconnection of family members can help alleviate potential negative outcomes.

This is especially true for parent-child relationships in stepfamilies. Thus far research has focused primarily on analyzing dyadic relationships in the context of these transitions. In this particular analysis I move from the examination of the relationship between one parent and their child to inspect relationship typologies that incorporate EAs and their (a) resident parent, (b) nonresident parent, and (c) stepparent. This is consistent with the life course notion of linked lives. Each parental figure has an impact on EA outcomes and may impact the relationship the other parental figures have with the EA.

Due to the important role these parent-child relationships play in later life outcomes, it is also important to examine factors that might influence these relationships. Transitions are a time of upheaval during which family equilibrium is disrupted. During more normative transitions such as the birth or marriage of a child, it is often simpler to establish new family routines and processes. When this change is not normative or is generally unexpected, as divorce and stepfamily relationships often are, it can cause greater stress and thus take longer to regain a sense of equilibrium. This is reflected in research from the stepfamily field, which indicates that 
the longer stepfamilies exist and the younger the age at which an individual enters the stepfamily the more likely they are to report positive parent-child relationships in their stepfamilies (Golish, 2003; Hetherington, Henderson, \& Reiss, 1999; Stewart, 1999). These two ideas are reflective of the concepts of time and timing found in life course theory, and are used as factors predicting the quality of parent-child relationships.

In addition to time and timing, I will also examine the marital status of the resident parent and stepparent. As stated previously, transitions are a time of upheaval in stepfamily life. I propose that this upheaval might be further aggravated by whether or not the stepfamily was begun with the marriage versus the cohabitation of the resident and parental figures. Stepfamily researchers have recently begun to explore the impact of parental cohabitation on stepfamily life. The research that has been done, which I will examine in more depth later, indicates that cohabiting stepfamilies experience more continued parent-child relationship strain than married stepfamilies (Brown \& Rinelli, 2010; Manning \& Lamb, 2003).

Ultimately, I use life course theory, in conjunction with both family systems and gender theory, to guide my examination of the development and impact of parent-child relationships. First, I identify the patterns of parent-child relationships that develop in married and cohabiting stepfamilies. Following the identification of these patterns, I examine how time, timing, parental marital status, EA sex, and stepparent sex influence parental relationships. Finally, I examine how membership in these different typologies influences EA outcomes including depression, drug use, and risky sexual behavior.

\section{Patterns of Parent-Child Relationships}

Much of the research conducted thus far on parent-child relationships in stepfamilies has focused on the impact of a single parental figure on child outcomes and adjustment. This lack of 
a more holistic perspective that includes all three parental figures may be why researchers find so much variety in the development of relationships between parents and children in stepfamilies (Amato, 1993; Dunn, Cheng, O’Connor, \& Bridges, 2004; King, 2006; King 2007). Life course theory emphasizes the importance of acknowledging families as interconnected, with each member playing an influential role in the lives and relationships of the other members of the family system (Elder et al., 2003). These collective relationships between children and their parents may help to explain why some individuals who report close ties with biological parents or stepparents still have negative outcomes. After all some EAs may report having a distant relationship with their stepparent while still remaining close to their biological parents and their outcomes may differ from other EAs who report a different kind of relationship pattern. It is also possible that beneficial outcomes experienced both during and following stepfamily life may lean more heavily on which parent(s) a child develops positive relationships with rather than the simple presence of one or two positive parental relationships.

But what factors contribute to parent-child relationships? Concepts such as warmth and closeness between parents and their children are consistently used when examining parent-child relationships in stepfamilies (Baxter, Braithwaite, \& Bryant, 2007; Faber \& Wittenborn, 2010; King, Amato, \& Lindstrom, 2015). In fact, Amato et al. (2016) used reports of warmth and closeness to examine the types of parent-child relationship patterns reported by adolescents. However, warmth and closeness are not the only factors that contribute to parent-child relationships in stepfamilies. Also present in research are the ideas of involved parenting and communication that can be heavily impacted by stepfamily life (Afifi \& Keith, 2004; Bray \& Berger, 1993; Coleman, Fine, Ganong, Downs, \& Pauki, 2001; Ganong, Coleman, Fine, \& Martin, 1999; King et al., 2015). Together, involved parenting and quality communication 
reduce boundary ambiguity and deviant behaviors, and lead to better adjustment in stepfamily life (Cartwright \& Seymour, 2002; Golish, 2003; Schrodt, 2006). Using all three of these features of parenting (i.e. communication, involved parenting, and warmth/closeness), I will examine the relationship patterns EAs report developing with their (a) resident parent, (b) nonresident parent, and (c) stepparent.

\section{Predictors of Parent-Child Relationship Quality}

Previous research examining the patterns of parent-child relationships that form during stepfamily life has primarily focused on married stepfather families (Amato et al., 2016). While remarriage is the most commonly accepted form of stepfamily formation, Bumpass, Raley and Sweet (1995) argue that stepfamilies need to be acknowledged based on living arrangements not just marital status. Considering $15 \%$ of children whose parents separate during their life are expected to experience mother cohabitation by age 12 (Kennedy \& Bumpass, 2008), this is an important distinction for researchers to make. The few articles that compare married and cohabiting stepfamilies have found that children in cohabiting stepfamilies experience more negative outcomes than their peers in married stepfamilies (Brown, 2006; Brown \& Rinelli, 2010; Manning \& Lamb, 2003; Wu, Hou, \& Schimmele, 2008). Because cohabiting stepfamilies may increase ambiguity in stepfamily life (Manning \& Lamb, 2003) and lead to reduced stepfather investment (Hofferth \& Anderson, 2003), EAs who experience this type of stepfamily setting may be less likely to report close connections with either of their residential parents, thus resulting in more negative outcomes.

Similar to cohabiting stepfamilies, stepmothers require more attention in stepfamily literature. While stepfather families have statistically remained more dominant, $20 \%$ of children living in married stepfamilies in 2012 were living with their father and stepmother (U.S. Census 
Bureau, 2014). While stepsons appear to benefit more than stepdaughters from the entrance of a stepfather (Amato \& Keith, 1991; Foley et al., 2004; Santrock, Warshak, Lindberg, \& Meadows, 1982), research is sparse regarding the different impact of stepmothers versus stepfathers (Amato, 1993). It is possible that because stepmothers are more likely to fill the role of kinkeeper, individuals who experienced this type of stepfamily may be more likely to report close relationships with fathers and stepmothers (Schmeeckle, 2007). In addition, children in stepmother families might be more likely than stepfather families to report close relationships with their nonresident mother, who appears to continue a rather steady involvement even after a child enters a stepfamily (Bronstein, Stoll, Clauson, Abrams, \& Briones, 1994; Hawkins, Amato, \& King, 2006; King, 2007; Seltzer, 1991; Stephens, 1996; Stewart, 1999). The gender of the parents and children in stepfamilies appears to have a complex and contradictory effect on child outcomes. A deeper understanding of gender effects may result in a more adequate acknowledgement of the complexity of the stepfamily experience.

Two other factors that have received more attention in stepfamily research, but may benefit from the more holistic perspective utilized in the current analysis, are the ideas of time and timing presented in life course theory (Elder et al., 2003). Research has indicated that, over time, the relationship between the resident parent and stepparent tend to improve as stepfamilies begins to stabilize (Golish, 2003; Hetherington et al., 1999), while nonresident parental relationships — at least in the case of nonresident fathers - often weaken (Bronstein et al., 1994; Seltzer, 1991; Stephens, 1996; Stewart, 1999). Yet even these trends may differ depending on the age at which an individual enters a stepfamily. Although there is, to my knowledge, no research that directly compares differences in those who enter stepfamily life as children versus adolescents, adolescents are often more independent of their family system than are younger 
children and may be more likely to seek out their nonresident parent or peers for support rather than turning to their step- or resident parent (Aquilino, 2006; Bray, 1988; Bray \& Berger, 1993; Hetherington, 1992; Hetherington \& Jodl, 1994). This may result in adolescents being more likely to have weaker relationships with some or all of their parental figures.

In summary, six predictors of parent-child relationships will be examined in this study. These predictors include: (a) whether the stepfamily was formed by remarriage or the cohabitation of the resident parent and stepparent, (b) the sex of the EA, (c) the sex of the stepparent, (d) how long the stepfamily has existed, (e) the age of the EA when the stepfamily formed and (f) the quantity of time spent with the nonresident parent.

\section{The Impact of Stepfamily Life on Emerging Adults}

Yet another slow-filling gap in stepfamily literature focuses on how parental relationships in stepfamilies influence EA outcomes. EA is a prolonged period of identity exploration distinct from adolescence (Arnett, 2000). Identity development is not generally obtained until after high school when more emphasis is placed on becoming self-sufficient in preparation for adult roles (Montemayor, Brown, \& Adams, 1985). This includes identifying potential careers, and the use of job experience or education attainment to obtain them. In addition, the EA years are a time for seeking out and establishing long-term relationships that often involve an exploration of sexuality (Arnett, 2000; Halpern \& Kaestle, 2014). These important EA processes may be deterred by the development of negative internalizing and externalizing behaviors in childhood and adolescence.

How might EAs be influenced by experiencing stepfamily life in childhood or adolescence? While there are few studies I am currently aware of that approach the answer to this question, it is possible to glean some knowledge from studies on children and adolescents 
who experience stepfamily life. As discussed previously, entering a stepfamily can cause a large amount of upheaval in the parent-child relationship. This can also lead children and adolescents to experience weakened attachment to their parents (Barrett \& Turner, 2006) raising the likelihood of developing depression (Garnefski \& Diekstra, 1997; Gordon, 2003; Gilman Kawachi, Fitzmaurice, \& Buka, 2003; Spruijt \& Goede, 1997). Depression appears to be one internalizing behavior that is particularly likely to spill over into emerging adulthood (Hankin et al., 1998; Lu, Mueser, Rosenberg, \& Jankowski, 2008; Sheets \& Craighead, 2014). As children and adolescents experience feelings or separation from parents, and nonrestrictive parenting styles, illegal drug use is another negative outcome that may develop (Barrett \& Turner, 2006; Chassin, Pitts, \& Prost, 2002; Crawford \& Novak, 2008; Hoffmann, 2002; Kendler, Ohlsson, Sundquist, \& Sundquist, 2014). Tucker, Ellickson, Orlando, Martino, and Klein (2005) found that individuals who begin using drugs during early adolescence and begin to escalate in drug use during the transition into emerging adulthood are particularly susceptible to negative outcomes such as dependence on controlled substances, stealing, selling drugs, exhibiting violent behaviors, and poor physical and mental health in emerging adulthood (see also Flewelling \& Bauman, 1990; Hoffmann \& Johnson, 1998; Kandel \& Logan, 1984).

In addition to depression and drug use, adolescents in stepfamilies are also more likely to participate in risky sexual behaviors. It is possible that because children with divorced parents are more likely to experience low levels of commitment in relationships (Amato \& DeBoer, 2001), they may be drawn to the noncommittal nature of hooking up as both adolescents and EAs (Owen et al., 2010). Unfortunately, EAs who are drawn to these behaviors are at higher risk of physically detrimental outcomes such as sexually transmitted infections (STI; Heldman \& Wade, 2010), heightened guilt, remorse (Owen, et al. 2010), increased feeling of depression and 
loneliness (Owen, Fincham, \& Moore, 2011), and unwanted sex (Peterson \& Muehlenhard, 2007).

\section{Current Study}

The data used for this study comes from a cross-sectional, restrospective survey examining EAs' experience with their stepfamily during childhood and adolescence. Using the life course perspective in this analysis implies a need to use longitudinal data. Scott and Alwin (1998) noted that longitudinally designed studies can be collected both prospectively (e.g. through multiple reports of present experiences overtime) or retrospectively (e.g., reports on past experiences). Retrospective data may be biased because the potential influence of present circumstances on past experiences may cause a recall bias in respondents (Scott \& Alwin, 1998). However, due to time, monetary, and in some cases ethical constraints both retrospective and prospective data are necessary in research. For example, retrospective data is found to be most appropriate in cases where individuals are asked to reflect on how previous behavior influences current behavior (Scott \& Alwin, 1998). Because the current analysis examines how previous life experiences impact the present behavior of EAs, the use of retrospective data is appropriate in our analysis.

Both research (Amato et al., 2016) and theory (Elder et al., 2003) portray the importance of acknowledging the interconnected nature of stepfamily relationships in the examination of parental impact on child outcomes. The first goal of my study is to use parental warmth, involved parenting and communication to identify patterns of relationships that develop in stepfamilies. For example, in one relationship pattern EAs may report having a distant relationship with their stepparent while still remaining close to their biological parents and their outcomes may differ from other EAs who report a pattern of close relationships with all three parental figures. The 
relationship patterns examined here will include the relationship quality the EAs reported developing with their: (a) resident parent, (b) nonresident parent, and (c) stepparent. The second goal is to examine the factors that influence the formation of these different individual patterns.

To do this I will examine how six factors influence the patterns of parent-child relationships that form in stepfamilies: (a) whether the stepfamily was formed by remarriage or the cohabitation of the resident parent and stepparent, (b) the sex of the EA, (c) the sex of the stepparent, (d) how long the stepfamily has existed, (e) the age of the EA when the stepfamily formed and (f) the quantity of time spent with the nonresident parent. Finally, I will examine how the different patterns of parent-child relationship patterns that form influence EA outcomes, including depression, illegal drug use, and hooking up behaviors.

Specific hypotheses are difficult to determine due to the lack of research examining all three parent-child relationships in stepfamilies, especially when the number and types of classes are still unknown. Based on the research of Amato and his colleagues (2016) as well as information gleaned from the wider field of parent-child relationships in stepfamilies, I would expect there to be a class characterized by high quality relationships with their resident parents, a class where low quality relationships with all three parents is reported, and finally a class where the EA reports high quality relationships with all three parents. While this third class is not reflected in the classes found by Amato et al. (2016), it is possible that because we include stepmother families there will be a higher likelihood of EAs reporting close relationships with their nonresident parents. I further hypothesize that EAs who entered their stepfamily at a young age, spent more time as part of a stepfamily and had a married resident and stepparent will be more likely to develop high quality relationships with multiple stepfamily families. Finally, I 
hypothesize that EAs who report having high quality relationships with all three parental figures will be at lowest risk for depression, drug use, and hooking up behaviors.

\section{Method}

\section{Sample}

The study sample contains 1,159 EAs, age $18-30(\mathrm{M}=24.78, \mathrm{SD}=3.91)$ who lived in a stepfamily between the ages of 8 and 18 called the Stepfamily Experience Project (STEP; Jensen, Shafer, \& Holmes, 2015). Qualtrics, an American research firm specializing in data collection for universities, non-profits, and corporations procured the sample. Qualtrics used a quota sampling method to ensure that the socio-demographics of the sample matched US Census estimates of racial/ethnic composition and educational attainment of American EAs. My sample is unique in many ways. Not only is it a national sample of EAs who all grew up in stepfamilies, it also contains EAs who lived in married and cohabiting stepfamilies, and includes both stepmother and stepfather families. Having a national quota sample of this size allowed me to represent EAs from diverse educational experiences, stepfamily incomes, racial backgrounds, and family structures including not only stepfather and stepmother families but also cohabiting and married stepfamilies. Overall, 675 respondents were female with 484 male EAs. Nearly half the sample reported having participated in some college $(42.8 \%)$ or actually completing a college degree (31.8\%). The sample primarily consisted of White, non-Hispanic young adults (60\%), with 9\% Black, 8\% Hispanic, 2\% Asian, 1\% Native American, and 20\% reporting mixed ethnicity. Many of the participants reported no income (11\%), another $31 \%$ reported income below $\$ 20,000,43 \%$ were between $\$ 20,000$ and $\$ 59,999$, the remainder made over $\$ 60,000$ a year. Of the sample, $31 \%$ reported living with a stepmother versus a stepfather $(69 \%)$. 
Cohabiting stepfamilies made up $21 \%$ of the sample and married stepfamilies $79 \%$. Due to the lack of homosexual stepfamilies in this dataset, I included only heterosexual couples.

\section{Measures}

Parent-child relationship quality. Three separate scales were created for the (a) resident parent, (b) stepparent, and (c) nonresident parent based on questions taken from Relationship Evaluation of the Individual, Family, Cultural, and Couple Contexts (RELATE; Busby, Holman, \& Taniguchi, 2004). Each scale consisted of three items reflecting three dimensions of parental relationship quality commonly used in stepfamily literature: warmth, communication, and involved parenting (King, 2006; King et al., 2015; Stewart, 2007). EAs were asked to what degree they agreed with statements such as: "My residential biological parent maintained a close and warm relationship with me."; "My residential stepparent was a good parent to me"; and "I was able to communicate openly and safely with my nonresidential biological parent." For the stepparent the questions about warmth and closeness differed slightly: "My residential stepparent formed a close and warm relationship with me." Response options ranged from $1=$ strongly disagree to $5=$ strongly agree, and all items were coded such that higher values indicated better parent-child relationships with the respondent. Cronbach's alpha reflected high reliability for the resident parent $(\alpha=.89)$, stepparent $(\alpha=.93)$, and nonresident parent $(\alpha=.94)$. See Table 1 for additional descriptive statistics.

Independent variables. Six predictive measures were included in this analysis: marital status of the resident parent and stepparent, sex of the EA, sex of the stepparent, years spent in a stepfamily, the age that the participant entered their stepfamily and the quantity of time spent with the nonresident parent. Marital status used a single question inquiring what type of relationships the parent was in with her or his new partner. Due to the phrasing of this question, 
it is difficult to know if the new relationship began as a cohabiting relationship, which later transitioned into marriage. Unfortunately, we do not have the data to capture this potential change, and we assume that the EA would report the current parental marital status of their step and resident parents. Information for parental marital status, EA sex, and stepparent sex is found in the "Participants" section above. To ascertain the years spent in a stepfamily participants were asked to indicate how many years they had lived in a stepfamily household. Answers ranged from 0-30 $(M=10.44, S D=5.67)$. Age at stepfamily formation was based on a question asking what age participants were when their stepfamily first formed. Answers ranged from 8-29 $(M=$ 8.60, $S D=4.62$ ). Quantity of time spent with the nonresident biological parent was based on a question that asked the average percentage of time the participant spent with the nonresident parent $(M=24.31, S D=26.47$ : see Table 1$)$.

Outcomes. Depressive symptoms. This variable was computed using a short scale of the Center for Epidemiological Studies Depression Scale (Cole, Rabin, Smith, \& Kaufman, 2004; Radloff, 1977). Participants were asked to mark on a 4-point scale $(0=$ rarely or none of the time (less than once a week), and 3= most or all of the time (5-7 days a week)) how often they had experienced feelings such as failure, loneliness, and that people were treating them unfairly ( $\alpha=$ .75). Higher scores indicate more depressive symptoms.

Illegal drug use. This scale was pulled from questions on the Relationship Evaluation Questionnaire (RELATE; Busby, et al., 2004). The question inquired how often in the last twelve months participants had smoked marijuana. This variable was dichotomous with $0=n o$ marijuana use, and $1=$ used marijuana at least once a month or more.

Hooking up. This variable was based on one question from the Relationship Evaluation Questionnaire (RELATE; Busby et al., 2004) asking how frequently the participant had hooked 
up with a stranger. The variable was dichotomous with $0=$ no hooking up, and $1=$ hooked up at least once a month or more. See Table 1 for descriptive statics on all outcomes variables.

\section{Analysis}

In this article I used latent class analysis (LCA) to identify the parent-child relationship patterns that form in stepfamilies. LCA is particularly useful for identifying subgroups in relatively homogenous groups (McCutcheon, 1987). Unlike cluster analysis, LCA calculates the probability an individual has for having membership in any of the estimated typologies (McCutcheon, 1987), while accounting for the uncertainty of classification in the between-class comparisons. In the current study I used stepwise latent class modeling originally employing $\mathrm{BCH}$ weights with classification error rates fixed (Masyn, 2017). Unfortunately, some $\mathrm{BCH}$ values resulted in some negative weight solutions which are not admissible in this kind of analysis. In response I used the class probabilities in the Mplus training command and the probabilities option instead of the $\mathrm{BCH}$ weights to ascertain class membership. Although $\mathrm{BCH}$ weights are preferred for fixing class membership, there was very little difference in outcomes when using the class probabilities.

Using Mplus 7.4, I conducted a full class enumeration process (without independent variabless or distal outcomes) to determine the optimal number of latent classes that fit these data (Masyn, 2017; Nylund-Gibson \& Masyn, 2016). When the final unconditional latent class model was estimated, individuals were classified into their most likely latent classes (i.e. modal classification or cmod), and classification error rates were calculated and exported (i.e. bch weights are calculated and exported; Asparouhov, \& Muthén 2014; Asparouhov \& Muthén, 2015). The latent class parent-child relationship 
variables were then regressed on the independent variables using the modal classification from step 2 with classification error rates fixed (from the step 2 estimation). Independent variables include the marital status of the resident parent and stepparent, the sex of the EA, the sex of the stepparent, years spent in a stepfamily, the age that the participant entered their stepfamily, and the quantity of time spent with the nonresident parent.

In the final step the distal outcomes of depression, drug use and hooking up behavior were be added to this process (please see Masyn, 2017 for a full description of this stepwise latent class modeling procedure). To evaluate the between-class differences for each distal outcome, I constrained the means to be the same across all classes then used Wald's test to determine whether constraining the means worsened model fit. If the overall tests indicated the presence of significant differences between classes, then I conducted pairwise t-tests constraining individual class means and once again using Wald's test to see if there were significant differences between classes.

\section{Results}

\section{Correlations of All Study Variables}

A correlation analysis was run between class indicators, independent variables, and distal outcomes. Resident parent relationship quality was significantly correlated with resident stepparent relationship quality $(r=.58, p<.001)$, nonresident parent relationship quality $(r=$ $.16, p<.001)$, stepparent relationship status $(r=.07, p<.05)$, stepparent sex $(r=.09, p<.05)$, EA sex $(r=-.07, p=.02)$, years spent in the stepfamily $(r=.16, p<.001)$, depression $(r=-$ $.37, p<.001)$, and illegal drug use $(r=-.09, p<.05)$. Resident stepparent relationship quality was significantly correlated with nonresident parent relationship quality $(r=.14, p<.001)$, years spent in the stepfamily $(r=.18, p<.001)$, quantity of time spent with the nonresident parent $(r$ 
$=.09, p<.05)$ and depression $(r=-.34, p<.001)$. Nonresident parent relationships quality was significantly correlated with stepparent $\operatorname{sex}(r=-.20, p<.001)$, years spent in the stepfamily $(r$ $=-.12, p<.001)$, age the participant entered their stepfamily $(r=.09, p<.05)$, quantity of time spent with the nonresident parent $(r=.30, p<.001)$, and depression $(r=-.11, p<.05)$. See Table 2 for additional correlation statistics.

Correlations indicate that there is a significant relationship between individual class indicators and many of the independent variables. This seems to indicate that the independent variable will influence the patterns of parent-child relationship quality in the stepfamily. While there are fewer significant relationships shown between the class indicators and distal outcomes, the purpose of this paper is to learn if a collective look at all three parent-child relationships may more clearly depict the influence of stepfamily life on EA outcomes. There is something key about looking at the collective relationship between the effect of the relationship quality between all three parent-child relationships and these outcomes.

\section{Latent Class Identification}

The LCA analysis identified 6 distinct parent-child relationship patterns. See Table 3 for model fit information. Class 1 contained $11.3 \%$ of the sample, and participants reported low parent-child relationship quality among all parents. Class 2 contained $7.2 \%$ of the sample and reported a high quality relationship with their nonresident parent, but a low quality relationship with both resident parents. Class 3 contained 19.6\% of the sample, and participants reported high quality relationships with resident parents and a distant relationship with the nonresident parent. Class 4 contained $9.7 \%$ of the sample and was characterized by a midrange relationship with the resident biological parent that decreased from the stepparent to the nonresident parent respectively. Class 5 contained midrange relationships with all three parental figures (21.6\%). 
Finally, Class 6 , which contained $30 \%$ of the sample, reported high quality relationships with all three parental figures. See Figure 2 for more clarification on classes. Please continue to refer to Figure 2 as I discuss the results.

Entropy was .83 for the 6-class model. Although this entropy is not as high as desired, other indicators including the AIC, BIC, and both the VLMR and LMR p-values indicate that the 6-class model is best. Additionally, the parametric bootstrap showed 5 successful draws. Table 3 contains all model fit statistics for classes.

After identifying classes, I used t-tests to examine significant differences between class indicators. While some individual indicators were not significantly different across classes, when all three indicators were taken into account, each class was significantly different from the others. See Table 4 for more information on difference between class indicators.

\section{Multinomial Regression}

Multinomial regression analyses tested the relationship between the independent variables and class membership. Independent variables included the resident parent and stepparent's marital status, EA's sex, stepparent's sex, years spent in a stepfamily, the age that the participant entered their stepfamily and the quantity of time spent with the nonresident parent. Unstandardized coefficients and standard errors are on Tables 5-10 below.

Resident parents' marital status. The resident parents, which included the resident biological parent and resident stepparent, were more likely to be married in class $3(b=.62, p=$ $.02)$ and class $6(b=.54, p=.02)$ than in class 1 . Resident parents were also more likely to be married in class 6 than class $5(b=.34, p=.04$; See Table 5).

Emerging adult sex. Participants were more likely to be male in class $3(b=-.50, p=$ $.02)$ and class $6(b=-.40, p=.049)$ than class 1 . Participants were also more likely to be male in 
class $3(b=-.64, p=.01)$, class $5(b=-.50, p=.04)$, and class $6(b=-.54, p=.03)$ than class 2 (see Table 6).

Stepparent sex. Participants from stepfather families were more likely to be in class 3 ( $b$ $=1.11, p<.001)$ and class $4(b=.53, p=.003)$ than class 1 . These participants were also more likely to be in class $3(b=.13, p<.001)$ and class $4(b=.76, p=.009)$ than class 2 . Participants from stepmother families were more likely to be in class $4(b=-.58, p=.02)$, class $5(b=-1.03$, $p<.001)$, and class $6(b=-1.02, p<.001)$ than class 3 . They were also more likely to be in class $5(b=-.46, p=.03)$ and class $6(b=-.44, p=.04)$ than class 4 (See Table 7).

Years spent in the stepfamily. Participants who spent less time in a stepfamily were more likely to be in class 2 than class $1(b=-.13, p<.001)$. They were also more likely to be in class 4 than class $3(b=-.06, p=.005)$. Those who spent more years in a stepfamily were more likely to be in class 3 than class $1(b=.08, p=.003)$. More years in a stepfamily was also associated with membership in class $3(b=.21, p<.001)$, class $4(b=.15, p<.001)$, class $5(b$ $=.14, p<.001)$, and class $6(b=.17, p<.001)$ than class 2 . They were also more likely to be in class 6 than class $5(b=.03, p=.04$; See Table 8$)$.

Age of the emerging adult when the stepfamily formed. Participants were more likely to have entered the stepfamily at a younger age in class 2 than class $1(b=-.08, p=.02)$, class 3 $(b=.12, p<.001)$, class $5(b=.08, p=.004)$ and class $6(b=.11, p<.001$; See Table 9$)$.

Quantity of time spent with nonresident parent. Participants reported less time with their nonresident parents in class $3(b=-.02, p<.001)$ and class $4(b=-.02, p<.001)$ than class 2. Participants who reported spending more time with their nonresident parents were more likely to be in class $2(b=.02, p=.002)$, class $5(b=.01, p=.03)$ and class $6(b=.02, p<.001)$ than class 1 . They were also more likely to be in class $5(b=.02, p=.001)$ and class $6(b=.03, p<$ 
.001) than class 3. More time spent with nonresident parents was also associated with membership in class $5(b=.02, p=.001)$ and class $6(b=.03, p<.001)$ over class 4 . Finally, participants who reported a greater quantity of time with nonresident parents were also more likely to be in class 6 than class $5(b=.01, p=.001$; See Table 10$)$.

\section{ANOVA Distal Outcomes}

An ANOVA method was used to test the impact of class membership on distal outcomes. In each distal outcome there were significant differences across class membership. As a precaution, I tested the independent variables and controls to make sure they would not influence results (Galovan, Drouin, \& McDaniel, 2018). See Table 11 for details.

Depression. Class differences in depression are the most clear-cut as the ANOVA analysis resulted in three groups that each contained two classes. The two classes associated with the lowest levels of depression are class $3(M=.7 .33, S E=.37)$ and class $6(M=6.81, S E=$ .28). Conversely, the two classes associated with the highest levels of depression were class 1 ( $M$ $=13.53, S E=.60)$ and class $2(M=12.64, S E=.60)$. Class $4(M=10.08, S E=.50)$ and class 5 $(M=9.204, S E=.32)$ reported means that fell between those of the first and second groups. The addition of controls had no significant impact on depression.

Illegal drug use. The only significant differences across classes when it came to drug use were between class 1 and classes 3 and 6 . Individuals in class $1(M=.30, S E=.08)$ were significantly more likely to use drugs than those in class $3(M=.10, S E=.03)$ or class 6 ( $M=$ $.10, S E=.03)$. The addition of controls had no significant impact on illegal drug use.

Hooking up. Class $1(M=.49, S E=.09)$ was significantly different from class $2(M=$ $.16, S E=.04)$, class $3(M=.26, S E=.04)$, and class $4(M=.26, S E=.04)$. EAs in class 1 were 
more likely to participate in hooking up. Class 2 was also significantly different from class $6(M$ $=.33, S E=.04)$. EAs in class 2 were less likely to hook up than those in class 6 .

When all the independent variables were added as controls the difference between class 2 and class 6 was no longer significant. Conversely, when only stepparent sex was controlled for, class 2 became significantly different from class 3 and class 4 . Finally, when controlling for the sex of the EA, class 1 became significantly different from class 5 and class 6 . Correlations indicate that EA sex is significantly associated with hooking up, with male participants being more likely to hook up than females. I ran a regression between the two variables and found that EA sex was a significant predictor of hook up behaviors. The impact of stepparent sex was less clear as there was no significant correlation between stepparent sex and hooking up.

\section{Discussion}

Due to the amount of results present in this analysis, I find it prudent to focus the discussion on the most significant findings. The most important finding to highlight is the diversity of patterns found in the LCA results. The analysis resulted in 6 distinct patterns of parent-child relationship quality as reported by the EAs in the sample (See Figure 1). These results highlight the variability that is present in the parent-child relationships that form in stepfamilies. This variability must be assessed to help researchers and practitioners determine why some children are doing well in stepfamilies while others are not.

While the presence of multiple classes was expected, the fact that $30 \%$ of our sample reported having high quality relationships with all three parental figures was surprising. Membership in this group was associated with the lowest levels of EA depression and illegal drug use, as hypothesized. Additionally, there was no significant difference in depression and drug use for individuals in class 6 who reported having high quality relationships with all three 
parental figures and those that reported high quality relationships with only their resident parents (class 3). When adding together the percentages of those belonging to classes 3 and 6, just over $50 \%$ of our sample reported membership in the classes associated with the most positive outcomes. Such results indicate that, despite the negative outcomes associated with stepfamily life in prior variable-centered research (Hetherington, Cox, \& Cox, 1985; Sheets \& Craighead, 2014), a person-centered approach illuminates variability in outcomes for EAs in stepfamilies, whereby at least half of this current sample is likely to experience lower depression and drug use.

Further, because classes 3 and 6 have such similar outcomes, despite the significant differences in the quality of nonresident parent relationships, some may conclude that the relationship with the non-resident parent is not important. I think this would be a false conclusion and warn against it. I offer at least three points of caution and clarification here. First, this analysis does not include information regarding why these non-resident parents are not involved or when their involvement reduced or stopped. This likely varies, and likely contributes to the other process within the stepfamily. Future research should explore these nuances to better understand the nature of non-resident parent involvement in stepfamilies. Second, when examining these patterns from a systemic view, differences across classes suggest that nonresident parental figures do appear to matter in the context of the quality of the relationship with other parental figures. For example, EAs in class 6 who report the highest quality relationships with all three parental figures appear to be doing the best across all outcomes. Third, despite these nuances, we do think it is accurate to conclude that the quality of one's relationships with parental figures reduces the likelihood that EAs will experience depression and use illegal drugs. Asking EAs about the quality of their relationship with multiple parental figures gives researchers a clearer picture of the stepfamily system, and acknowledges variability 
within stepfamilies that leads to a better understanding of both risk factors and resilience in this family form.

As expected, when compared to class 1, EAs in class 3 and 6 were more likely to report that their resident parents were married and to have spent more time in their stepfamily. Less expected were the findings regarding the influence of biological sex and age at stepfamily formation. Classes 3 and 6 significantly differed from each other when it came to stepparent sex, with stepmother families more likely to be in class 6 , which contained higher quality relationships with the nonresident parent than class 3 . This was not all together surprising consider the fact that I assumed the presence of class 6 because I included stepmother families in my analysis. What was surprising was that there was not difference between classes 3 and 6 when it came to EA gender. According to the analysis EAs in classes 3 and 6 were more likely to be male, while EA females were more likely to report membership in classes 1 and 2 . Unfortunately, I can make no claims regarding the relationship between the gender of the EA adults and the gender of the parental figures based on this analysis. It is possible that an examination of multiple potential figures and the examination of different gender dyads (i.e. stepmother-stepdaughter, father-daughter, stepfather-stepson) is necessary to draw some more clear cut conclusions regarding the dichotomy between child and parent gender.

As for findings on the age at stepfamily formation, preliminary results indicated that age at stepfamily formation would have an inverse relationship with the years spent in the stepfamily. That is, the more years spent in a stepfamily, the younger the participant's age when his or her stepfamily formed. As a result I expected that classes 3 and 6 would not only be characterized by more years spent in the stepfamily, but also by EAs entering these stepfamilies at a younger age when compared to class 1 where all relationships were distant. However, this 
was not the case. Instead EAs in classes 3 and 6 showed no significant difference from class 1 and were expected to be older when they entered the stepfamily when they were compared to class 2 . This seeming inconsistency in results is potentially a result of limitations in this project. In particular, the data we used did not examine whether or not the participants experienced multiple stepfamily formations, how long each lasted, or which one they were reporting on. It is widely accepted that the more family disruption a child experiences, the more negative experiences they have. It is possible that those who entered their stepfamily at a young age, but experienced stepfamily disruption multiple times may have more negative outcomes than those who entered stepfamily life later, but did not experience additional disruption.

\section{Limitations}

The most influential limitation of this analysis is that it is cross-sectional and retrospective rather than longitudinal. As previously stated, retrospective data has the potential for bias (Scott \& Alwin, 1998). It is possible that some of the EAs in our sample report high quality relationships with (step)parents now because their current relationship is more positive than the relationships they had while living in the stepfamily home. Additionally, cross-sectional data, even if it is retrospective, is not as accurate as longitudinal data when it comes to measuring change across time. Thus, it is important for other studies to continue to address these issues in other samples.

\section{Conclusion}

The results of the LCA established the presence of 6 distinct patterns of parent-child relationships as reported by our sample of EAs (See Figure 1). Research acknowledging and assessing variability within stepfamilies is just beginning (Amato et al., 2016). In her decade review, Sweeney (2010) called for this type of person-centered work, acknowledging that 
variability within stepfamilies also illuminates probable variability in children's outcomes. Too often researchers emphasize between group differences by comparing children of divorce, or those in stepfamilies, with children whose parents have been stably married over time. While these between group comparisons are important, recognizing variability within groups allows scholars to discover aspects of stepfamilies that may also be associated with positive outcomes for children, adolescents, and EA. This can then lead to the development of even more effective programs and therapies to assist stepfamilies in their transitions. 


\section{References}

Afifi, T. D., \& Keith S. (2004). A risk and resiliency model of ambiguous loss in postdivorce stepfamilies. Journal of Family Communication 4(2), 65-98.

Amato, P. R. (1993). Children's adjustment to divorce: Theories, hypotheses, and empirical support. Journal of Marriage \& Family, 55(1), 23-38.

Amato, P. R., \& DeBoer, D. D. (2001). The transmission of marital instability across generations: Relationship skills or commitment to marriage? Journal of Marriage \& the Family, 63, 1038-1051.

Amato, P., \& Keith, B. (1991). Parental divorce and the well-being of children: A meta-analysis. Psychological Bulletin, 110(1), 26-46.

Amato, P. R., King, V., \& Thorsen, M. L. (2016). Parent-child relationships in stepfather families and adolescent adjustment: A latent class analysis. Journal of Marriage \& Family, 78(2), 482-497.

Aquilino, W. S. (2006). The noncustodial father-child relationship from adolescence into young adulthood. Journal of Marriage \& Family, 68(4), 929-946. doi: dx.doi.org/10.1111/j.17 41-3737.2006.00305.x

Arnett, J. J. (2000). Emerging adulthood: A theory of development from the late teens through the twenties. American Psychologist, 55(5), 469-480. http://doi.org/10.1037/0003066X.55.5.469

Asparouhov, T., \& Muthén, B. (2014). Auxiliary variables in mixture modeling: Three-step approaches using M plus. Structural Equation Modeling: A Multidisciplinary Journal, 21(3), 329-341. 
Asparouhov, T., \& Muthén, B. (2015). Auxiliary variables in mixture modeling: Using the BCH method in Mplus to estimate a distal outcome model and an arbitrary secondary model. Retrieved fromhttp://www.statmodel.com/examples/webnotes/webnote21.pdf

Barrett, A. E., \& Turner, R. J. (2006). Family structure and substance use problems in adolescence and early adulthood: Examining explanations for the relationship. Addiction, 101(1), 109-120. doi:10.1111/j.1360-0443.2005.01296.x

Baxter, L. A., Braithwaite, D. O., \& Bryant, L. E. (2007). Types of communication triads perceived by young-adults stepchildren in established stepfamilies. Communication Studies, 57(4), 381-400. doi: 10.1080/10510970600945923

Bornstein, M. (2002). Handbook of parenting: Being and becoming a parent. Mahwah, NJ: Erlbaum.

Bray, J. H. (1988). Children's development during early remarriage. In E. M. Hetherington \& J. D. Aratesh (Eds.), Impact of divorce, single parenting, and stepparenting on children (pp. 279-298). Hillsdale, NJ: Lawrence Erlbaum Associates

Bray, J. H., \& Berger, S. H. (1993). Developmental issues in stepfamilies research project: Family relationships and parent-child interactions. Journal of Family Psychology, 7, 7690.

Bronstein, P., Stoll, M. F., Clauson, J., Abrams, C. L., \& Briones, M. (1994). Fathering after separation or divorce: Factors predicting children's adjustment. Family Relations, 43(4), 469-479.

Brown, S. L. (2006). Family structure transitions and adolescent well-being. Demography, 43(3):447-461. 
Brown, S. L., \& Rinelli, L. N. (2010). Family structure, family processes, and adolescent smoking and drinking. Journal of Research on Adolescence, 20(2), 259-273.

Bumpass, L. L., Raley, R. K., \& Sweet, J. A. (1995). The changing character of stepfamilies: Implications of cohabitation and nonmarital childbearing. Demography, 32, 425-436. doi:10.2307/2061689

Busby, D. M., Holman, T. B., \& Tanniguchi, N. (2004). RELATE: Relationship evaluation of individual, family, cultural, and couple contexts. Family Relations, 50(4)

Cartwright, C. \& Seymour, F. (2002). Young adults' perceptions of parents' responses in stepfamilies. Journal of Divorce \& Remarriage, 37(3-4), 123-41.

Chassin, L., Pitts, S. C., \& Prost, J. (2002). Binge drinking trajectories from adolescence to emerging adulthood in a high-risk sample: Predictors and substance abuse outcomes. Journal of Consulting \& Clinical Psychology, 70(1), 67.

Cole, J. C., Rabin, A. S., Smith, T. L., \& Kaufman, A. S. (2004). Development and validation of a Rasch-derived CES-D short form. Psychological Assessment, 16(4), 360-372.

Coleman, M., Fine, M., Ganong, L., Downs, K., \& Pauk, N. (2001). When you're not the Brady Bunch: Identifying perceived conflicts and resolution strategies in stepfamilies. Personal Relationships, 8, 55-73.

Coleman, M., Ganong, L., \& Russell, L. T. (2013). Resilience in stepfamilies. In D. S. Becvar (Ed.), Handbook of family resilience (pp. 85-103). New York: Springer. doi:10.1007/978-1-4614-3917-2_6

Crawford, L. A., \& Novak, K. B. (2008). Parent-child relations and peer associations as mediators of the family structure-substance use relationship. Journal of Family Issues, 29(2), 155-184. doi:10.1177/0192513X07304461 
Du Plooy, K., \& Van Rensburg, E. (2015) Young adults' perception of coping with parental divorce: A retrospective study. Journal of Divorce \& Remarriage, 56(6), 490-512, doi: $10.1080 / 10502556.2015 .1058661$

Dunn, J., Cheng, H., O’Connor, T. G., \& Bridges, L. (2004). Children's perspectives on their relationships with their nonresident fathers: Influences, outcomes and implications. The Journal of Child Psychology and Psychiatry, 45(3), 553-566. doi: 10.1111/j.14697610.2004.00245.x

Eisinga, R., te Grotenhuis, M., \& Pelzer, B. (2013). The reliability of a two-item scale: Pearson, Cronbach, or Spearman-Brown? International Journal of Public Health, 58(4), 637-642. doi:10.1007/s00038-012-0416-3

Elder, G. H. (1998). The life course as developmental theory. Child Devlopment, 69(1), 1-12. doi: 10.1111/j.1467-8624.1998.tb06128.x

Elder, G. H., Johnson, M. K., \& Crosnoe, R. (2003). The emergence and development of life course theory (pp. 3-19). New York, NY: Kluwer Academic/Plenum Publishing

Faber, A. J. \& Wittenborn, A. K. (2010). The role of attachment in children's adjustment to divorce and remarriage, Journal of Family Psychotherapy, 21(2), 89-104. doi: $10.1080 / 08975353.2010 .483625$

Flewelling, R. L., \& Bauman, K. E. (1990). Family structure as a predictor of initial substance use and sexual intercourse in early adolescence. Journal of Marriage \& Family 52(1), 171-181. doi: 10.1111/j.1467-8624.2007.01091.x

Foley, D. L., Pickles, A., Rutter, M., Gardner, C. O., Maes, H. H., Silberg, J. L., \& Eaves, L. J. (2004). Risks for conduct disorder symptoms associated with parental alcoholism in 
stepfather families versus intact families from a community sample. Journal of Child Psychology \& Psychiatry, 45(4), 687-696.

Galovan, A. M., Drouin, M., \& McDaniel, B. T. (2018). Sexting profiles in the United States and Canada: Implication for individual and relationship well-being, Computers in Human Behavior, 79, 19-29.

Ganong, L. H., \& Coleman, M. (2017). Stepfamily relationships: Development, dynamics, and interventions (2nd ed.). New York, NY: Kluwer Academic/Plenum Publishers.

Ganong, L, Coleman, M., Fine, M., \& Martin, P. (1999). Stepparents’ affinity-seeking and affinity-maintaining strategies with stepchildren. Journal of Family Issues, 20(3), 299327.

Garnefski, N., \& Diekstra R. F. W. (1997). Adolescents from one parent, stepparent, and intact families: Emotional problems and suicide attempts. Journal of Adolescence 20, 201-8

Gilman, S. E., Kawachi, I., Fitzmaurice, G. M., \& Buka, S. L. (2003). Family disruption in childhood and risk of adult depression. American Journal of Psychiatry 160, 939-46.

Golish, T. D. (2003). Stepfamily communication strengths: Understanding the ties that bind. Human Communication Research, 29(1), 41-80.

Gordon, J.M. (2003). The long term effects of divorce and remarriage (Unpublished doctoral dissertation). George Mason University, Virginia.

Halpern, C. T., \& Kaestle, C. E. (2014). Sexuality in emerging adulthood. In D. L. Tolman, L. M. Diamond, J. A. Bauermeister, W. H. George, J. G. Pfaus, L. M. Ward (Eds.), APA handbook of sexuality and psychology, Vol. 1: Person-based approaches (487-522). Washington, DC, US: American Psychological Association. 
Hankin, B. L., Abramson, L. Y., Moffitt, T. E., Silva, P. A., McGee, R., \& Angell, K. E. (1998). Development of depression from preadolescence to young adulthood: Emerging gender differences in a 10-year longitudinal study. Journal of Abnormal Psychology, 107(1), 128.

Hawkins, D. N., Amato, P. R., \& King, V. (2006). Parent-adolescent involvement: The relative influence of parent gender and residence. Journal of Marriage \& Family, 68(1), 125-136. doi: $10.1111 / \mathrm{j} .1741-3737.2006 .00238 . x$

Heldman, C., \& Wade, L. (2010). Hook-up culture: Setting a new research agenda. Sexuality Research \& Social Policy, 7(4), 323-333.

Hetherington, E. M. (1992). Coping with marital transitions: A Family Systems Perspective. In. E. M. Hetherington, \& W. G. Glingempeel (Eds.), Monographs of the Society for Research in Child Development. 57, (2-3, Serial No. 227), 1-14.

Hetherington, E. M., Cox, M., \& Cox, R. (1985). Long-term effects of divorce and remarriage on the adjustment of children. Journal of the American Academy of Child Psychiatry, 24, $518-530$.

Hetherington, E. M., Henderson, S. H., \& Reiss, D. (1999). Adolescent siblings in stepfamilies: Family functioning and adolescent adjustment. Monographs of the Society for Research in Child Development 64(4), 1-25.

Hetherington, E. M., \& Jodl, K. M. (1994). Stepfamilies as settings for child development. In A. Booth \& J. Dunn. (Eds.), Stepfamilies: Who benefits? Who does not? (pp. 55-80). Hillsdale, NJ: Lawrence Erlbaum Associates

Hofferth, S. L., \& Anderson, K. G. (2003). Are all dads equal? Biology versus marriage as a basis for paternal investment. Journal of Marriage \& Family, 65(1), 213-232. 
Hoffmann, J. P. (2002). The community context of family structure and adolescent drug use. Journal of Marriage \& Family, 64(2), 314-330. https://doi.org/10.1111/j.1741-3737.200 2.00314.x

Hoffmann, J., \& Johnson, R. (1998). A national portrait of family structure and adolescent drug use. Journal of Marriage \& Family, 60(3), 633-645. doi:10.2307/353534

Jensen, T. M., Shafer, K., \& Holmes, E. K. (2015). Transitioning to stepfamily life: The influence of closeness with biological parents and stepparents on children's stress. Child \& Family Social Work, 22(1), 275-286. doi: 10.111/cfs.12237

Kandel, D. B., \& Logan, J. A. (1984). Patterns of drug use from adolescence to young adulthood: I. Periods of risk for initiation, continued use, and discontinuation. American Journal of Public Health, 74(7), 660-666.

Kendler, K. S., Ohlsson, H., Sundquist, K., \& Sundquist, J. (2014). Peer deviance, parental divorce, and genetic risk in the prediction of drug abuse in a nationwide Swedish sample: Evidence of environment-environment and gene-environment interaction. JAMA Psychiatry, 71(4), 439-445.

Kennedy, S., \& Bumpass, L. (2008). Cohabitation and children's living arrangements: New estimates from the United States. Demographic Research, 19, 1663-1692. 10.4054/DemRes.2008.19.47

King, V. (2006). The antecedents and consequences of adolescents' relationships with stepfathers and nonresident father. Journal of Marriage \& Family, 68(4), 910-928.

King, V. (2007). When children have two mothers: Relationships with nonresident mothers, stepmothers, and fathers. Journal of Marriage \& Family, 69(5), 1178-1193. 
King, V., Amato, P. R., \& Lindstrom, R. (2015). Stepfather-adolescent relationship quality during the first year of transitioning to a stepfamily. Journal of Marriage and Family, 77(5), 1179-1189. doi: 10.1111/jomf.12214

Lu, W., Mueser, K. T., Rosenberg, S. D., \& Jankowski, M. K. (2008). Correlates of adverse childhood experiences among adults with severe mood disorders. Psychiatric Services, 59(9), 1018-1026.

Manning, W. D., \& Lamb, K. A. (2003). Adolescent well-being in cohabiting, married, and single-parent families. Journal of Marriage \& Family, 65(4), 876-893.

Masyn, K. (2017). Measurement invariance and differential item functioning in latent class analysis with stepwise multiple indicator multiple cause modeling [Supplemental material]. Structural Equation Modeling: A Multidisciplinary Journal, 24(2), 180-197. doi:10.1080/10705511.2016.1254049

McCutcheon, A. L. (1987). Latent class analysis. Sage University Paper Series on Quantitative Applications in the Social Sciences, series no.07-064, Newbery Park, CA: Sage.

Minuchin, P. (1985). Families and individual development: Provocations from the field of family therapy. Child Development, 56(2), 289-302. doi: 10.2307/1129720

Montemayor, R., Brown, B., \& Adams, G. (1985). Changes in identity status and psychological adjustment after leaving home and entering college. In biennial meeting of the Society of Research on Child Development, Toronto, Ontario, Canada.

Nylund-Gibson, K. \& Masyn, K. E. (2016). Covariates and mixture modeling: Results of a simulation study exploring the impact of misspecified effects on class enumeration. Structural Equation Modeling: A Multidisciplinary Journal, 23(6), 782-797, doi: $10.1080 / 10705511.2016 .1221313$ 
Owen, J., Fincham, F. D., \& Moore, J. (2011). Short-term prospective study of hooking up among college students. Archives of Sexual Behavior, 40(2), 331-341.

Owen, J. J., Rhoades, G. K., Stanley, S. M., \& Fincham, F. D. (2010). "Hooking up” among college students: Demographic and psychosocial correlates. Archives of Sexual Behavior, 39(3), 653-663.

Peterson, Z. D., \& Muehlenhard, C. L. (2007). Conceptualizing the "wantedness" of women's consensual and nonconsensual sexual experiences: Implications for how women label their experiences with rape. Journal of Sex Research, 44(1), 72-88.

Radloff, L. S. (1977). The CES-D scale: A self-report depression scale for research in the general population, Applied Psychological Measurement, 1(3), 385-401. doi:

$10.1177 / 014662167700100306$

Santrock, J. W., Warshak, R., Lindbergh, C., \& Meadows, L. (1982). Children's and parent's observed social behavior in stepfather families. Child Development, 53(2), 472-480. doi:10.2307/1128990

Schmeeckle, M. (2007). Gender dynamics in stepfamilies: Adult stepchildren's views. Journal of Marriage \& Family, 69(1), 174-189.

Schrodt, P. (2006). The stepparent relationship index: Development, validation, and associations with stepchildren's perceptions of stepparent communication competence and closeness. Personal Relationships, 13(2), 167-82.

Scott, J., \& Alwin, D. (1998). Retrospective versus prospective measurement of life histories in longitudinal research. In J. Z. Giele \& G. H. Elder (Eds.), Methods of life course research: Qualitative and quantitative approaches (98-128). Thousand Oaks, CA: SAGE. 
Seltzer, J. A. (1991). Relationships between fathers and children who live apart: The father's role after separation. Journal of Marriage \& Family, 53(1), 79-102.

Sheets, E. S., \& Craighead, W. E. (2014). Comparing chronic interpersonal and noninterpersonal stress domains as predictors of depression recurrence in emerging adults. Behavior Research \& Therapy, 63, 36-42.

Spruijt, E., \& de Goede, M. (1997). Transitions in family structure and adolescent well-being. Adolescence, 32, 897-911.

Stephens, L. S. (1996). Will Johnny see Daddy this week? Journal of Family Issues, 17(4), 466494.

Stewart, S. D. (1999). Nonresident mothers' and fathers' social contact with children. Journal of Marriage \& Family, 61(4), 894-907.

Stewart, S. D. (2007). Brave new stepfamilies: Diverse paths toward stepfamily living. Thousand Oaks, CA: Sage.

Sweeney, M. M. (2010). Remarriage and stepfamilies: Strategic sites for family scholarship in the 21st century. Journal of Marriage \& Family, 72(3), 667-684.

Tucker, J. S., Ellickson, P. L., Orlando, M., Martino, S. C., \& Klein, D. J. (2005). Substance use trajectories from early adolescence to emerging adulthood: A comparison of smoking, binge drinking, and marijuana use. Journal of Drug Issues, 35(2), 307-332. doi:10.1177/002204260503500205

U.S. Census Bureau (2014). Adopted children and stepchildren: 2010. Retrieved from: https://www.census.gov/content/dam/Census/library/publications/2014/demo/p20572.pdf 
Wu, Z., Hou, F., \& Schimmele, C. M. (2008). Family structure and children's psychosocial outcomes. Journal of Family Issues, 29(12), 1600-1624. 
Table 1. Descriptive statistics.

\begin{tabular}{lccc}
\hline \multicolumn{1}{c}{ Variable Names } & Means & SD & Range \\
\hline Resident parent relationship quality & 3.72 & 1.21 & $1-5$ \\
Resident stepparent relationship quality & 3.19 & 1.34 & $1-5$ \\
Nonresident parent relationship quality & 3.06 & 1.42 & $1-5$ \\
Years spent in the stepfamily & 10.45 & 5.61 & $0-30$ \\
Age entered stepfamily & 8.62 & 4.62 & $0-30$ \\
Quantity of time spent with nonresident parent & 24.31 & 26.47 & $0-100$ \\
Depression & 8.92 & 6.46 & $0-33$ \\
Drug use & .15 & .65 & $0-5$ \\
Hooking up & .31 & .80 & $0-5$ \\
\hline
\end{tabular}


Table 2. Correlations of class indicators, independent variables, and distal outcomes.

\begin{tabular}{|c|c|c|c|c|c|c|c|c|c|c|c|c|}
\hline Model Fit Statistics & 1 & 2 & 3 & 4 & 5 & 6 & 7 & 8 & 9 & 10 & 11 & 12 \\
\hline $\begin{array}{l}\text { 1.Resident parent } \\
\text { relationship quality }\end{array}$ & -- & & & & & & & & & & & \\
\hline $\begin{array}{l}\text { 2. Resident stepparent } \\
\text { relationship quality }\end{array}$ & $.58 * *$ & -- & & & & & & & & & & \\
\hline $\begin{array}{l}\text { 3. Nonresident parent } \\
\text { relationship quality }\end{array}$ & $.16^{* *}$ & $.14^{* *}$ & -- & & & & & & & & & \\
\hline $\begin{array}{l}\text { 4.Step relationship } \\
\text { status }\end{array}$ & $.07 *$ & -.01 & -.01 & -- & & & & & & & & \\
\hline 5.Stepparent sex & $.09 * *$ & .01 & $-.20 * *$ & .001 & -- & & & & & & & \\
\hline 6.EA sex & $-.07 *$ & -.02 & -.001 & .02 & $.09 *$ & -- & & & & & & \\
\hline $\begin{array}{l}\text { 7. Years spent in the } \\
\text { stepfamily }\end{array}$ & $.16^{* *}$ & $.18 * *$ & $-.12 * *$ & $.09^{*}$ & $.11 * *$ & .03 & -- & & & & & \\
\hline $\begin{array}{l}\text { 8.Age entered } \\
\text { stepfamily }\end{array}$ & -.02 & -.03 & $.09 * *$ & $-.09 *$ & $-.11 * *$ & $-.07 *$ & $-.58 *$ & -- & & & & \\
\hline $\begin{array}{l}\text { 9. Quantity of time } \\
\text { spent with } \\
\text { nonresident parent }\end{array}$ & .01 & $.09 *$ & $.30 * *$ & $-.07 *$ & $-.27 * *$ & .01 & -.01 & .02 & -- & & & \\
\hline 10.Depression & $-.37 * *$ & $-.34 * *$ & $-.1 * *$ & $-.1 * *$ & -.003 & .05 & -.04 & .02 & -.01 & -- & & \\
\hline 11.Illegal drug use & $-.09 * *$ & -.05 & -.05 & $-.06 *$ & -.04 & $-.08 *$ & .02 & .01 & -.05 & $.13 * *$ & -- & \\
\hline 12.Hooking up & -.04 & -.01 & -.03 & $-.06 *$ & -.03 & $-.28 * *$ & .02 & .004 & .008 & $.09 *$ & $.28 * *$ & -- \\
\hline
\end{tabular}


Table 3. Model fit statistics for determining number of classes.

\begin{tabular}{lrrrrrrrr}
\hline Model Fit Statistics & 2-Class & 3-Class & 4-Class & 5-Class & 6-Class & 7-Class & 8-Class & 9-Class \\
\hline AIC & 11130.13 & 10944.31 & 10799.01 & 10686.40 & 10597.10 & 10543.33 & 10426.93 & 10371.56 \\
BIC & 1118.68 & 11015.09 & 10890.01 & 10797.62 & 10728.54 & 10694.99 & 10598.81 & 10563.66 \\
Adj. BIC & 11148.92 & 10970.62 & 10832.83 & 10727.74 & 10645.96 & 1599.70 & 10490.81 & 10442.96 \\
VLMR LRT test (p-value) & 0 & 0 & .06 & 0 & .005 & .41 & 0.67 & .098 \\
LMR Adj. LRT test (p-value) & 0 & 0 & .07 & 0 & .006 & .42 & 0.67 & .10 \\
Parametric Bootstrapped (p-value) & 0 & 0 & 0 & 0 & 0 & 0 & 0 \\
Entropy & 0.86 & 0.81 & 0.83 & 0.83 & 0.83 & 0.84 & 0.84 & 0.83 \\
\hline
\end{tabular}


Table 4. T-tests of difference between classes.

\begin{tabular}{lcccccc}
\hline & Class 1 & Class 2 & Class 3 & Class 4 & Class 5 & Class 6 \\
\cline { 2 - 7 } Class Indicators & Mean & Mean & Mean & Mean & Mean & Mean \\
\hline Resident Parent & $1.66_{\mathrm{a}}$ & $1.68_{\mathrm{a}}$ & $4.72 \mathrm{~b}$ & $3.33_{\mathrm{c}}$ & $3.46 \mathrm{~d}$ & $4.63 \mathrm{~b}$ \\
Resident Stepparent & $1.89 \mathrm{a}$ & $1.86_{\mathrm{a}}$ & $3.99_{\mathrm{b}}$ & $2.42_{\mathrm{c}}$ & $2.84_{\mathrm{d}}$ & $3.96 \mathrm{~b}$ \\
Nonresident Parent & $1.49_{\mathrm{a}}$ & $4.25_{\mathrm{b}}$ & $1.56_{\mathrm{a}}$ & $1.48_{\mathrm{a}}$ & $3.52_{\mathrm{c}}$ & $4.35 \mathrm{~b}$ \\
\hline
\end{tabular}

Note: Different subscripts indicate significant difference between means. For example, in the row labeled "Resident Parent" subscripts indicate significant differences between class 1 and class 3, but not significant difference between class 1 and class 2 . If you reference Figure 2 it shows that classes 1 and 2 both report low quality relationships with the resident parent, while class 3 indicants a close relationship with the resident parent. 
Table 5. Multinomial logistic regression of resident parent relationship status across classes.

\begin{tabular}{|c|c|c|c|c|c|c|c|c|c|c|}
\hline & \multicolumn{2}{|c|}{ Class 1} & \multicolumn{2}{|c|}{ Class 2} & \multicolumn{2}{|c|}{ Class 3} & \multicolumn{2}{|c|}{ Class 4} & \multicolumn{2}{|c|}{ Class 5} \\
\hline & $\mathrm{b}$ & (SE) & $\mathrm{b}$ & (SE) & $\mathrm{b}$ & (SE) & $\mathrm{b}$ & (SE) & $\mathrm{b}$ & (SE) \\
\hline Class 1 & -- & -- & & & & & & & & \\
\hline Class 2 & .57 & $(.32)$ & -- & -- & & & & & & \\
\hline Class 3 & .62 & $(.26)^{*}$ & .05 & $(.33)$ & -- & -- & & & & \\
\hline Class 4 & .18 & $(.25)$ & -.39 & $(.34)$ & -.44 & $(.24)$ & -- & -- & & \\
\hline Class 5 & .21 & $(.23)$ & -.36 & $(.29)$ & -.42 & $(.21)$ & .03 & $(.21)$ & -- & -- \\
\hline Class 6 & .54 & $(.23)^{*}$ & -.03 & $(.30)$ & -.08 & $(.21)$ & .36 & $(.23)$ & .34 & $(.17)^{*}$ \\
\hline
\end{tabular}

Notes: $*$ p-value $<.05, * *$ p-value $<.001$

To assist the interpretation of this table I included an example. The relationship status of the parents is a dichotomous variable with 0 representing cohabiting stepfamilies and 1 representing married stepfamilies. The column headings represent the reference groups for each individual column. For example, when looking at the coefficient and standard error for the row labeled Class 3, the positive coefficient indicates that married stepfamilies are more likely to be in class 3 (the comparison group) than class 1 (the reference group). 
Table 6. Multinomial logistic regression of EA sex across classes.

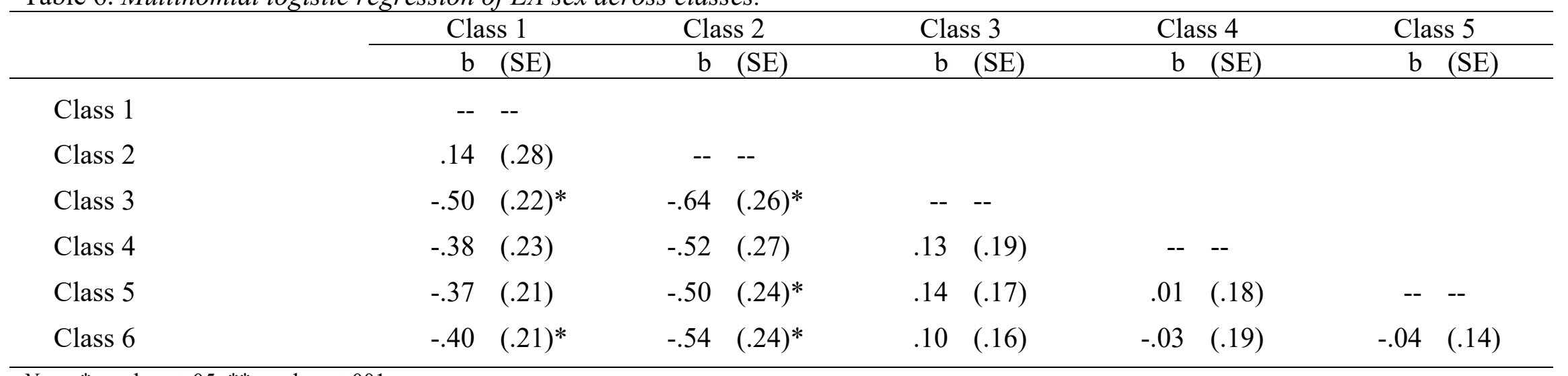

Note: $* \mathrm{p}$-value $<.05, * * \mathrm{p}$-value $<.001$

To assist the interpretation of this table I included an example. The relationship status of the parents is a dichotomous variable with 0 representing male participants and 1 representing female participants. The column headings represent the reference groups for each individual column. For example, when looking at the coefficient and standard error for the row labeled Class 3 the negative coefficient indicates that male participants are more likely to be in class 3 (the comparison group) than class 1 (the reference group). 
Table 7. Multinomial logistic regression of stepparent sex across classes.

\begin{tabular}{|c|c|c|c|c|c|c|c|c|c|c|}
\hline & \multicolumn{2}{|c|}{ Class 1} & \multicolumn{2}{|c|}{ Class 2} & \multicolumn{2}{|c|}{ Class 3} & \multicolumn{2}{|c|}{ Class 4} & \multicolumn{2}{|c|}{ Class 5} \\
\hline & $\mathrm{b}$ & (SE) & $\mathrm{b}$ & (SE) & $\mathrm{b}$ & (SE) & $\mathrm{b}$ & (SE) & $\mathrm{b}$ & $(\mathrm{SE})$ \\
\hline Class 1 & -- & -- & & & & & & & & \\
\hline Class 3 & 1.11 & $(.26)^{* *}$ & .13 & $(.29)^{* *}$ & -- & -- & & & & \\
\hline Class 4 & .53 & $(.25)^{*}$ & .76 & $(.29)^{*}$ & -.58 & $(.24)^{*}$ & -- & -- & & \\
\hline Class 6 & .09 & $(.22)$ & .32 & $(.25)$ & -1.02 & $(.21)^{* *}$ & -.44 & $(.22)^{*}$ & .02 & $(.15)$ \\
\hline
\end{tabular}

Note: $*$ p-value $<.05, * *$ p-value $<.001$

To assist the interpretation of this table I included an example. The relationship status of the parents is a dichotomous variable with 0 stepmother families and 1 representing stepfather families. The column headings represent the reference groups for each individual column. For example, when looking at the coefficient and standard error for the row labeled Class 3 the positive coefficient indicates that stepfather families are more likely to be in class 3 (the comparison group) than class 1 (the reference group). 
Table 8. Multinomial logistic regression of the years spent in a stepfamily across classes.

\begin{tabular}{|c|c|c|c|c|c|c|c|c|c|c|}
\hline & \multicolumn{2}{|c|}{ Class 1} & \multicolumn{2}{|c|}{ Class 2} & \multicolumn{2}{|c|}{ Class 3} & \multicolumn{2}{|c|}{ Class 4} & \multicolumn{2}{|c|}{ Class 5} \\
\hline & $\mathrm{b}$ & $(\mathrm{SE})$ & $\mathrm{b}$ & $(\mathrm{SE})$ & $\mathrm{b}$ & (SE) & $\mathrm{b}$ & (SE) & $\mathrm{b}$ & (SE) \\
\hline Class 1 & -- & -- & & & & & & & & \\
\hline Class 2 & -.13 & $(.03) * *$ & -- & -- & & & & & & \\
\hline Class 3 & .08 & $(.03)^{*}$ & .21 & $(.03)^{* *}$ & -- & -- & & & & \\
\hline Class 4 & .01 & $(.03)$ & .15 & $(.03)^{* *}$ & -.06 & $(.02)^{*}$ & -- & -- & & \\
\hline Class 5 & .01 & $(.03)$ & .14 & $(.03)^{* *}$ & -.01 & $(.02)$ & .01 & $(.02)$ & -- & -- \\
\hline Class 6 & .04 & $(.03)$ & .17 & $(.03)^{* *}$ & .02 & $(.02)$ & .03 & $(.02)$ & .03 & $(.02)^{*}$ \\
\hline
\end{tabular}

Note: $* \mathrm{p}$-value $<.05, * * \mathrm{p}$-value $<.001$

To assist the interpretation of this table I included an example. The relationship status of the parents is continuous with larger numbers equating more years in the stepfamily. The column headings represent the reference groups for each individual column. For example, when looking at the coefficient and standard error for the row labeled Class 2 the negative coefficient indicates that participants spent less time in their stepfamily in class 2 (the comparison group) than class 1 (the reference group). 
Table 9. Multinomial logistic regression of age at stepfamily formation across classes.

\begin{tabular}{|c|c|c|c|c|c|c|c|c|c|c|}
\hline & \multicolumn{2}{|c|}{ Class 1} & \multicolumn{2}{|c|}{ Class 2} & \multicolumn{2}{|c|}{ Class 3} & \multicolumn{2}{|c|}{ Class 4} & \multicolumn{2}{|c|}{ Class 5} \\
\hline & $\mathrm{b}$ & (SE) & $\mathrm{b}$ & (SE) & $\mathrm{b}$ & (SE) & $\mathrm{b}$ & (SE) & $\mathrm{b}$ & $(\mathrm{SE})$ \\
\hline Class 1 & -- & -- & & & & & & & & \\
\hline Class 3 & .03 & $(.03)$ & .12 & $(.03)^{* *}$ & -- & -- & & & & \\
\hline Class 4 & -.02 & $(.04)$ & .06 & (.04) & -.05 & $(.03)$ & -- & -- & & \\
\hline Class 6 & .03 & $(.03)$ & .11 & $(.03)^{* *}$ & -.001 & $(.02)$ & .05 & $(.03)$ & .03 & $(.02)$ \\
\hline
\end{tabular}

Note: $*$ p-value $<.05, * *$ p-value $<.001$

To assist the interpretation of this table I included an example. The relationship status of the parents is continuous with larger numbers meaning the participant was older when their stepfamily formed. The column headings represent the reference groups for each individual column. For example, when looking at the coefficient and standard error for the row labeled Class 2 the negative coefficient indicates that participants began their family at a younger age in class 2 (the comparison group) than class 1 (the reference group). 
Table 10. Multinomial logistic regression of the quantity of time spent with the nonresident parent across classes.

\begin{tabular}{|c|c|c|c|c|c|c|c|c|c|c|}
\hline & \multicolumn{2}{|c|}{ Class 1} & \multicolumn{2}{|c|}{ Class 2} & \multicolumn{2}{|c|}{ Class 3} & \multicolumn{2}{|c|}{ Class 4} & \multicolumn{2}{|c|}{ Class 5} \\
\hline & $\mathrm{b}$ & $(\mathrm{SE})$ & $\mathrm{b}$ & (SE) & $\mathrm{b}$ & $(\mathrm{SE})$ & $\mathrm{b}$ & (SE) & $\mathrm{b}$ & $(\mathrm{SE})$ \\
\hline Class 1 & -- & -- & & & & & & & & \\
\hline Class 2 & .02 & $(.01)^{*}$ & -- & -- & & & & & & \\
\hline Class 3 & -.01 & $(.01)$ & -.02 & $(.01)^{* *}$ & -- & -- & & & & \\
\hline Class 4 & -.01 & $(.01)$ & -.02 & $(.01)^{* *}$ & .01 & $(.01)$ & -- & -- & & \\
\hline Class 5 & .01 & $(.01)^{*}$ & -.01 & $(.004)$ & .02 & $(.01)^{*}$ & .02 & $(.01)^{*}$ & -- & -- \\
\hline Class 6 & .02 & $(.01)^{* *}$ & .001 & $(.004)$ & .03 & $(.01)^{* *}$ & .03 & $(.01)^{* *}$ & .01 & $(.002)^{*}$ \\
\hline
\end{tabular}

Note: $* \mathrm{p}$-value $<.05, * * \mathrm{p}$-value $<.001$

To assist the interpretation of this table I included an example. The relationship status of the parents is continuous with larger numbers equating more time spent with the nonresident parent. The column headings represent the reference groups for each individual column. For example, when looking at the coefficient and standard error for the row labeled Class 2 the positive coefficient indicates that participants spent more with their nonresident parent in class 2 (the comparison group) than class 1 (the reference group). 
Table 11. Means and SEs of class differences on distal outcomes.

\begin{tabular}{|c|c|c|c|c|c|c|}
\hline \multirow[b]{2}{*}{ Independent variables } & Class 1 & \multirow{2}{*}{$\begin{array}{c}\text { Class } 2 \\
\text { Mean (SE) }\end{array}$} & \multirow{2}{*}{$\begin{array}{c}\text { Class } 3 \\
\text { Mean (SE) }\end{array}$} & \multirow{2}{*}{$\begin{array}{c}\text { Class } 4 \\
\text { Mean (SE) }\end{array}$} & \multirow{2}{*}{$\begin{array}{r}\text { Class } 5 \\
\text { Mean (SE) } \\
\end{array}$} & \multirow{2}{*}{$\begin{array}{r}\text { Class } 6 \\
\text { Mean (SE) } \\
\end{array}$} \\
\hline & Mean (SE) & & & & & \\
\hline Depression & $13.53(.60)_{\mathrm{a}}$ & $12.64(.60)_{\mathrm{a}}$ & $7.33(.37)_{b}$ & $10.08(.50)_{\mathrm{c}}$ & $9.20(.32)_{\mathrm{c}}$ & $6.81(.28)_{b}$ \\
\hline Illegal drug use & $.30(.08)_{\mathrm{a}}$ & $.17(.07)_{\mathrm{a}, \mathrm{b}}$ & $.10(.03)_{b}$ & $.16(.05)_{\mathrm{a}, \mathrm{b}}$ & $.16(.03)_{\mathrm{a}, \mathrm{b}}$ & $.10(.03)_{\mathrm{b}}$ \\
\hline Hooking up & $.49(.09) \mathrm{a}$ & $.16(.04) \mathrm{b}$ & $.26(.04)_{b, c}$ & $.26(.04) b, c$ & $.31(.04)_{a, b, c}$ & $.33(.04)_{\mathrm{a}, \mathrm{c}}$ \\
\hline
\end{tabular}

Note: Different subscripts indicate significant difference between means.. 


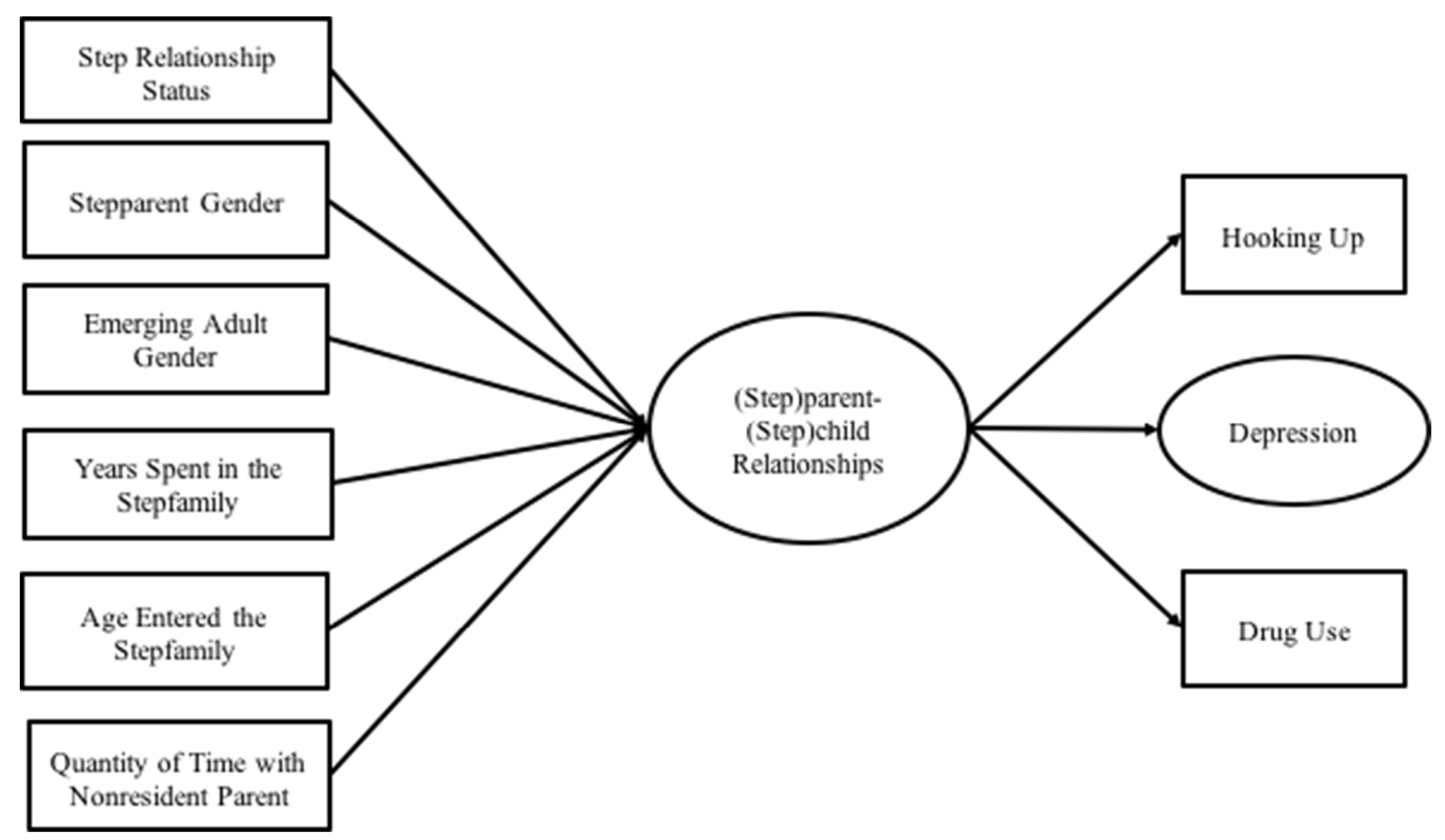

Figure 1. Analysis model. 


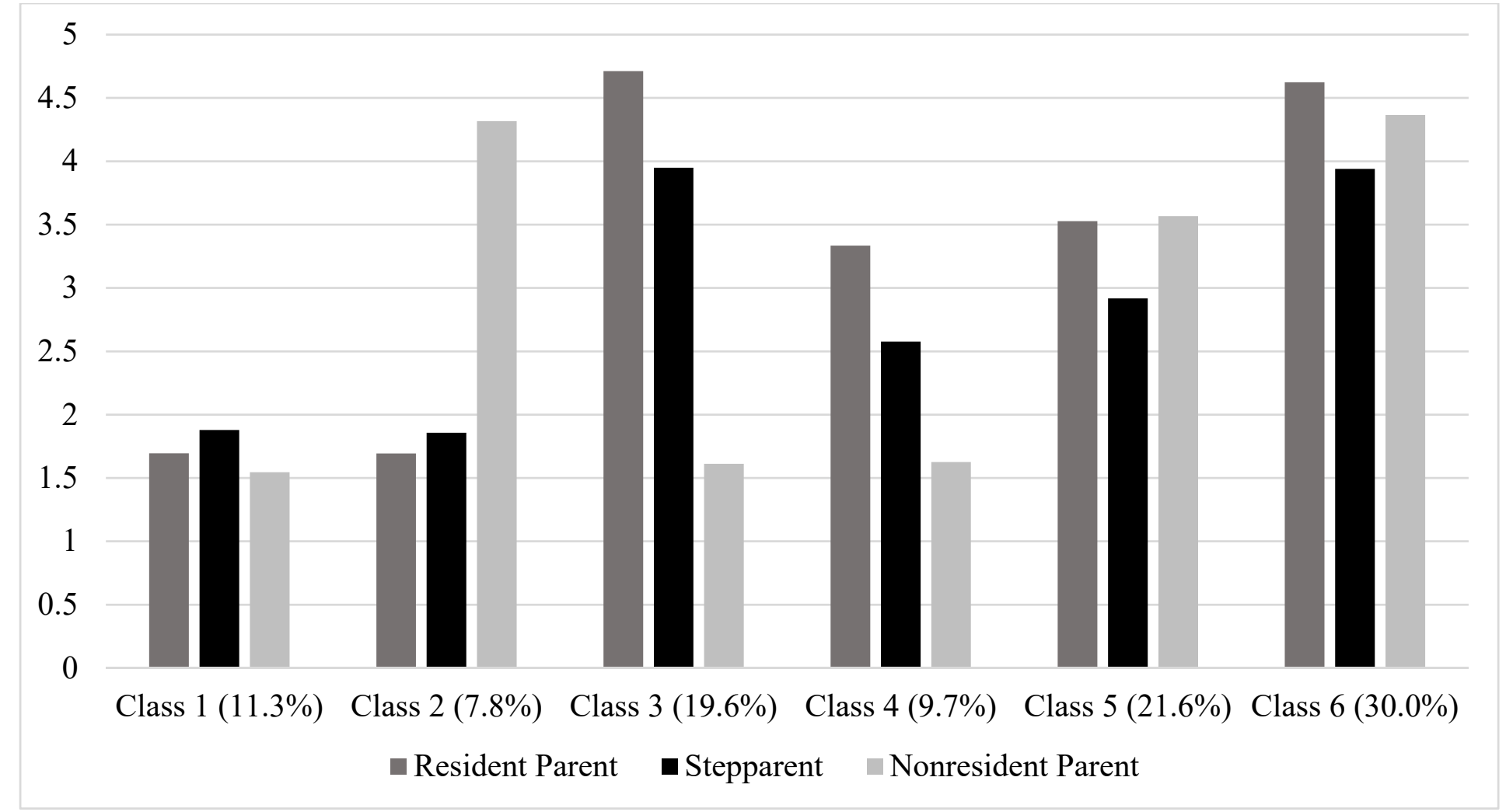

Figure 2. Latent classes of parent-child relationships. 